$\underline{\xi}=-m$

\title{
Protective role of ginseng extract against oxidative stress, reproductive and some biochemical parameters alterations induced by doxorubicin in male rats
}

\author{
Mohammed Kassem ${ }^{1}$, Abdel-Fattah Ali ${ }^{2 *}$, Seham. Y. Abo-kora ${ }^{3}$, Nesreen Shawky ${ }^{1}$ \\ ${ }^{1}$ Animal Health Institute (Zagazig branch), Egypt \\ ${ }^{2}$ Clinical Pathology department, Faculty of Veterinary Medicine, Benha University, Egypt \\ ${ }^{3}$ Pharmacology department, Faculty of Veterinary Medicine, Benha University, Egypt \\ *Corresponding author E-mail: abdelfatah.mohamed@fvtm.bu.edu.eg
}

\begin{abstract}
This study investigates the modulating effect of ginseng against testicular toxicity, oxidative stress and changes in some biochemical parameters induced by doxorubicin. Twenty male rats were divided into four groups. The 1 st group received distilled water orally (control group), The 2nd group received doxorubicin ( $5 \mathrm{mg} / \mathrm{kg}$ b.wt. intrapertenoineal) once a week for eight weeks, The $3 \mathrm{rd}$ group received ginseng extract $(200 \mathrm{mg} / \mathrm{kg}$ b.wt.) daily for eight weeks and the 4th group received doxorubicin with ginseng extract by the same doses as in the 2 nd and the 3 rd groups respectively. At the end of the 8th week, blood and semen samples were taken for biochemical and semen analysis, respectively. The doxorubicin treated group had significantly higher serum alanine aminotransferase (ALT), aspartate aminotransferase (AST), Creatine kinase (CK) and lactate dehydrogenase (LDH) along with lower levels of total protein, albumin and globulin. In addition, a significant decrease in antioxidant enzymes (SOD, CAT, GSHPx), and glutathione (GSH) associated with higher level of malondialdehyde (MDA) were observed. At the same time, the group that took doxorubicin with ginseng did not differ from control group in terms of these parameters. Male fertility study showed changes in testosterone and semen analysis in both groups treated with doxorubicin, while the group that took doxorubicin with ginseng showed an improvement towards control levels of these parameters. Thus ginseng supplement can reduce the negative effects of doxorubicin- induce.
\end{abstract}

Keywords: Antioxidant Status; Biochemical Parameters; Doxorubicin; Ginseng; Semen Analysis.

\section{Introduction}

Doxorubicin is antibiotic drug isolated from Streptomyces peucetius var. caesius (Arcamone et al. 1969, Frederick et al. 1990) which is first generation of anthracycline, a potent broad spectrum chemotherapeutic agent used for the treatment of several types of cancer (Sakr et al. 2013, Chen et al. 2016). It is used in treatment of breast, uterine, ovarian, bladder and lung cancers (Marinelo et al. 2018). Meanwhile, doxorubicin induce serious problems such as male infertility due to its harmful effect on testicular tissue, apoptosis and it is also decreases DNA synthesis with toxicities to different organs like kidney, heart and liver (Kato et al. 2001, Shivakumar et al. 2012, Yang et al. 2017). Many studies have been done to reduce doxorubicin toxicity by using numerous physical, chemical and/or biological techniques (Hellmann 1999). It was found that some herbal nutrients reduce the toxic effect of doxorubicin through its antioxidant effect (Shihong et al. 2014). Medicinal herbs were used to treat a wide range of health problems such as cancer (Jimenez et al. 2003). Ginseng is one of the most popular herbs in both Western and Eastern countries which known as a traditional Asian medicine for stimulation of sexual function (Hong et al. 2002). Commonly, Ginseng is used in herbal medicine (Park et al. 2013) as it contains high iodine content and saponins (Jang et al., 2011). Ginseng saponins (ginsenosides) have been studied and found to be responsible for some medicinal effects, specifically antihypertensive, anticancer, anti-stress and anti-diabetic effects (Issa \& El-Sherif 2017).

Panax ginseng is one of the most valued medicinal herbaceous plant belonged to the Araliaceae family (Kamel \& Lotfy 2006). Panax ginseng (Asian ginseng) is one of three main types of ginseng; the rest are American and Siberian ginseng. Panax ginseng was grown both in Korea and China. There are white Panax and red Panax. Red ginseng is considered more potent than the white (Nair et al. 2012). Clinically, Korean red ginseng enhances sexual functions (Jang et al. 2008).

Hypothesis usage of ginseng extract as antioxidant may reduce the adverse effect that resulted from doxorubicin administration (as anticarcinogenic drug) in rats. The objective of the present work is to evaluate the effect of doxorubicin on male fertility and biochemical parameters in rats and modulating effect of ginseng extract. 


\section{Material and methods}

\subsection{Drug}

2.1.1. Doxorubicin (Adricin) A product of EIMC united pharmaceuticals, Egypt (50 mg doxorubicin hydrochloride/ vial)

2.1.2. Ginseng Extract (Korean red ginseng extract) was obtained from Pharco Pharmaceuticals, Alexandria, Egypt, each capsule contain $100 \mathrm{mg}$ of ginseng extract

\subsection{Experimental rats and experimental design}

Twenty male albino rats, 5months old, $180-200 \mathrm{~g}$ body weight were used in this study. Rats were housed in metallic cages under hygienic condition and divided into 4 groups (5rats/each). The $1^{\text {st }}$ group received distilled water orally (control group), the $2^{\text {nd }}$ group (doxorubicin group) received doxorubicin ( $5 \mathrm{mg} / \mathrm{kg} \mathrm{b.wt.} \mathrm{intraperitoneal)} \mathrm{once} \mathrm{a} \mathrm{week} \mathrm{for} \mathrm{eight} \mathrm{weeks} \mathrm{(Brilhante} \mathrm{et} \mathrm{al.} \mathrm{2011),} \mathrm{the} 3^{\text {rd }}$ group (ginseng group) received $200 \mathrm{mg}$ ginseng extract $/ \mathrm{kg}$ b.wt. using stomach tube daily for eight weeks (Lee. et al., 2019), $4^{\text {th }}$ group received doxorubicin and ginseng extract by the same dosage of $2^{\text {nd }}$ group and 3rd group respectively. At the end of experiment, blood samples obtained in plain tubes to separate serum for biochemical analysis, antioxidant capacity evaluation and testosterone level determination. After that, rats were scarified and dissected to obtain epididymis for semen analysis.

\subsection{Biochemical evaluation}

Aspartate aminotransferase (AST) and alanine aminotransferase (ALT) were determined according to (Reitman \& Frankel 1957), Lactate dehydrogenase (LDH) was determined according to (Buhl \& Jackson 1978), Creatinine kinase (CK) was determined according to (Horder \& Elsner 1991), Total protein was determined according to (Doumas et al. 1981), Albumin was determined according to (Bauer 1982), Globulin was calculated as follow: Globulins =total protein -albumin.

\subsection{Antioxidant state evaluation}

Superoxide dismutase (SOD), Catalase (CAT) and Glutathione peroxidase (GSH-Px) were determined according to Nishikimi et al. (1972), Sinha (1972) and Paglia \& Valentine (1967), respectively. Glutathione (GSH) concentration was determined according to (Beutler et al. 1963). Malondialdehyde (MDA) was determined according to (Nielsen et al. 1997).

\subsection{Male fertility evaluation}

Content of epididymis tail of each rat was collected by squeezed gently in sterile watch glass containing $1 \mathrm{ml}$ sodium citrate solution $2.9 \%$ for semen analysis according to (Bearden \& Flaquary 1980). Serum testosterone hormone level was estimated by radioimmunoassay according to (Wilson \& Foster 1992).

\subsection{Statistical analysis}

The obtained data was analyzed by using computerized SPSS program (version 25) according to Tambane \&Dunlop (2000).

\section{Results}

\subsection{Biochemical results}

Regarding the changes in biochemical parameters, there was a significant increase in AST, ALT, LDH and CK activities along with a significant decrease in total protein, albumin and globulin levels in doxorubicin group in comparison with control group. Meanwhile, there was a significant decrease in AST, ALT, LDH and CK activities associated with non-significant changes in total protein and albumin levels in doxorubicin plus ginseng group when compared with doxorubicin group. Interestingly, non-significant changes were reported in total protein, albumin and globulin levels in doxorubicin plus ginseng group in comparison with control group. Albu$\mathrm{min} /$ Globulin ratio showed non-significant changes between different groups. Ginseng treated group showed non-significant changes in enzymes activities under investigation and protein profile when compared to control group as shown in Table 1.

\subsection{Antioxidant state results}

Concerning to antioxidant capacity, there was a significant increase in MDA level accompanied with a significant decrease in GSH concentration and CAT, SOD and GSH-Px activities in doxorubicin group in comparison with control group. In doxorubicin plus ginseng group, there was a significant increase in SOD activity and a significant decrease in MDA level along with non-significant changes in GSH concentration, CAT and GSH-Px activities when compared with doxorubicin group. At the same time, there were non-significant changes in MDA level, GSH concentration and CAT, SOD, and GSH-Px activities in doxorubicin plus ginseng group in comparison with control group. Importantly, Ginseng treated group showed a significant increase in GSH concentration and CAT, SOD, and GSH-Px activities along with non-significant changes in MDA level when compared with control group as shown in Table 2.

\subsection{Male fertility results}

With respect to semen analysis and testosterone hormone level, doxorubicin group showed a significant decrease in sperm count, sperm motility percent, live sperm percent and testosterone level along with a significant increase in total sperm abnormality percent when compared to control group. On the other hand, there was a significant increase in sperm count, sperm motility percent and live sperm percent associated with a significant decrease in total sperm abnormality percent in doxorubicin plus ginseng group in comparison with 
doxorubicin group. Testosterone level in doxorubicin plus ginseng group showed non-significant changes when compared with control group and doxorubicin group. Importantly, the rats treated with ginseng alone showed a significant increase in sperm count, sperm motility percent, live sperm percent and testosterone level accompanied with a significant decrease in total sperm abnormality percent when compared with control group as shown in Table 3.

Table 1: Serum Biochemical Parameters (Mean \pm SE) in Doxorubicin, Ginseng and Combined Groups after Eight Weeks

\begin{tabular}{lllll}
\hline & Control & Doxorubicin & Ginseng & Doxorubicin + Ginseng \\
\hline AST $(\mathrm{u} / \mathrm{l})$ & $78.32 \pm 1.38^{\mathrm{b}}$ & $94.53 \pm 1.53^{\mathrm{a}}$ & $76.78 \pm 1.21^{\mathrm{b}}$ & $73.12 \pm 1.59^{\mathrm{b}}$ \\
ALT $(\mathrm{u} / \mathrm{l})$ & $79.56 \pm 1.15^{\mathrm{b}}$ & $93.24 \pm 1.54^{\mathrm{a}}$ & $75.83 \pm 1.67^{\mathrm{b}}$ & $164.21 \pm 2.32^{\mathrm{b}}$ \\
LDH $(\mathrm{u} / \mathrm{l})$ & $168.17 \pm 2.16^{\mathrm{b}}$ & $226.06 \pm 2.62^{\mathrm{a}}$ & $129.16 \pm 3.59^{\mathrm{b}}$ & $176.23 \pm 2.54^{\mathrm{b}}$ \\
CK $(\mathrm{u} / \mathrm{l})$ & $132.34 \pm 3.22^{\mathrm{b}}$ & $165.87 \pm 4.44^{\mathrm{a}}$ & $7.83 \pm 0.89^{\mathrm{a}}$ & $140.23 \pm 3.73^{\mathrm{b}}$ \\
Total Protein $(\mathrm{g} / \mathrm{dl})$ & $6.67 \pm 0.32^{\mathrm{ab}}$ & $4.16 \pm 0.25^{\mathrm{c}}$ & $4.37 \pm 0.55^{\mathrm{a}}$ & $5.67 \pm 0.61^{\mathrm{bc}}$ \\
Albumin $(\mathrm{g} / \mathrm{dl})$ & $3.85 \pm 0.32^{\mathrm{b}}$ & $2.32 \pm 0.35^{\mathrm{c}}$ & $3.46 \pm 0.32^{\mathrm{a}}$ & $3.21 \pm 0.96^{\mathrm{bc}}$ \\
Globulin $(\mathrm{g} / \mathrm{l})$ & $2.82 \pm 0.44^{\mathrm{ab}}$ & $1.84 \pm 0.55^{\mathrm{c}}$ & $1.26 \pm 0.18^{\mathrm{a}}$ & $2.46 \pm 0.33^{\mathrm{b}}$ \\
A/G ratio & $1.37 \pm 0.24^{\mathrm{a}}$ & $1.26 \pm 0.20^{\mathrm{a}}$ & $1.30 \pm 0.22^{\mathrm{a}}$ & \\
\hline
\end{tabular}

Means in the same row with different superscript letters $(a, b, c)$ are significantly different at $\mathrm{P}<0.05$.

Table 2: MDA, CAT, SOD, GSH and GSH-Px in Doxorubicin, Ginseng and Combined Groups after Eight Weeks.

\begin{tabular}{lllll}
\hline & Control & Doxorubicin & Ginseng & Doxorubicin + Ginseng \\
\hline MDA $(\mu \mathrm{mol} / \mathrm{L})$ & $15.83 \pm 0.75^{\mathrm{bc}}$ & $24.45 \pm 0.94^{\mathrm{a}}$ & $11.32 \pm 0.45^{\mathrm{c}}$ & $19.89 \pm 0.73^{\mathrm{b}}$ \\
CAT $(\mathrm{u} / \mathrm{ml})$ & $23.57 \pm 1.21^{\mathrm{b}}$ & $11.34 \pm 1.27^{\mathrm{c}}$ & $27.35 \pm 1.81^{\mathrm{a}}$ & $19.98 \pm 1.41^{\mathrm{bc}}$ \\
SOD $(\mathrm{u} / \mathrm{ml})$ & $84.62 \pm 0.83^{\mathrm{b}}$ & $69.36 \pm 0.89^{\mathrm{c}}$ & $99.43 \pm 0.64^{\mathrm{a}}$ & $81.32 \pm 0.78^{\mathrm{b}}$ \\
GSH $(\mathrm{mmol} / \mathrm{L})$ & $79.14 \pm 4.51^{\mathrm{b}}$ & $58.35 \pm 4.73^{\mathrm{c}}$ & $93.45 \pm 3.92^{\mathrm{a}}$ & \\
GSHPx $(\mathrm{u} / \mathrm{ml})$ & $97.14 \pm 5.31^{\mathrm{b}}$ & $77.21 \pm 3.62^{\mathrm{c}}$ & $112.26 \pm 3.4^{\mathrm{a}}$ & \\
\hline
\end{tabular}

Means in the same row with different superscript letters $(a, b, c)$ are significantly different at $\mathrm{P}<0.05$.

Table 3: Semen Analysis and Testosterone Level in Doxorubicin, Ginseng and Combined Groups after Eight Weeks.

\begin{tabular}{|c|c|c|c|c|}
\hline & Control & Doxorubicin & Ginseng & Doxorubicin + Ginseng \\
\hline Sperm count $\left(\mathrm{x} 10^{6} / \mathrm{ml}\right)$ & $1.95 \pm 0.46^{\mathrm{b}}$ & $1.36 \pm 0.41^{\mathrm{c}}$ & $2.34 \pm 0.45^{\mathrm{a}}$ & $2.09 \pm 0.48^{\mathrm{b}}$ \\
\hline Sperm motility $(\%)$ & $80.87 \pm 0.89^{b}$ & $65.05 \pm 0.38^{\mathrm{c}}$ & $88.44 \pm 0.58^{a}$ & $78.26 \pm 0.54^{b}$ \\
\hline Live sperm $(\%)$ & $86.123 \pm 0.56^{\mathrm{b}}$ & $75.47 \pm 0.87^{\mathrm{c}}$ & $90.55 \pm 0.61^{\mathrm{a}}$ & $80.34 \pm 0.33^{b}$ \\
\hline Total abnormality (\%) & $14.23 \pm 0.23^{\mathrm{b}}$ & $37.23 \pm 0.69^{\mathrm{a}}$ & $10.0 \pm 0.42^{\mathrm{c}}$ & $16.43 \pm 0.59^{b}$ \\
\hline Testosterone (ng/ml) & $3.48 \pm 0.56^{\mathrm{b}}$ & $1.98 \pm 0.82^{\mathrm{c}}$ & $4.23 \pm 0.62^{\mathrm{a}}$ & $2.71 \pm 0.45^{\mathrm{bc}}$ \\
\hline
\end{tabular}

Means in the same row with different superscript letters $(a, b, c)$ are significantly different at $\mathrm{P}<0.05$.

\section{Discussion}

Concerning biochemical parameters, Rats that received doxorubicin showed significant elevation in AST, ALT, CK and LDH activities. These findings corroborate the findings of previous studies (Mohamed et al. 2015, Abdalla et al. 2016, Jun et al. 2017) in rats received doxorubicin. These result supported by Singh et al. (2008) who showed that doxorubicin induce toxicity and leakage of these enzymes. Increased activities of CK and LDH enzymes may be attributed to destruction of myocardial cells that induced by doxorubicin (Patil \& Balaraman 2009, Al-Sowayan \& Nadia 2014) as a result of oxidative stress occurred after doxorubicin administration (Fadya et al. 2019, Haybar et al. 2019). Additionally, a significant increase in AST and ALT activities may be due to their increased leakage from damaged and necrotic hepatocytes as a result of doxorubicin toxicity (Injac et al. 2008). Notably, Yagmurca et al. (2007) found that hepatic injury is attributed to doxorubicin ability to produce excess free radicals and lipid peroxides and to suppress free radicals scavenging capacity and antioxidant defensive mechanism.

Ginseng group revealed non-significant reduction in AST, ALT, CK and LDH activities in comparison with control group. Meanwhile, there was a significant decrease in AST, ALT, LDH and CK activities in doxorubicin plus ginseng group when compared with doxorubicin group. These findings are consistent with that obtained by Shihong et al. (2014) who reported that ginseng normalized liver and other organ functions and the serum enzyme activities (AST, ALT, CK and LDH). The obtained results may be due to ginseng protects cell membrane fatty acids from decomposition induced by free radicals (Okada \& Zhang 1998). Also, Akash et al. (2018) showed that ginsenoside Re (one constituent of ginseng) protect cardiac cells from oxidative damage as a result of its ability for scavenging of free radicals.

In the present study, doxorubicin induced significant reduction in serum total proteins, albumin and globulins. These results are consistent with (Sridevi 2011, Pugazhendhi et al. 2018, Vesna et al. 2018). Reduction in total protein and albumin may be due to damage of hepatocytes as a result of doxorubicin toxicity (Osama et al. 2019).

Ginseng induced non-significant increase in serum total proteins, albumin, globulins and A/G ratio compared with control group. These results are consistent with (Hess et al. 1982). They found that ginseng induced non-significant elevation in total protein, albumin and globulin. Also, Eskandari et al. (2017) found that ginseng induced non-significant elevation in total protein and globulin in rats. On the other hand, Doxorubicin plus ginseng group showed non-significant changes in total protein and albumin levels in comparison either with control group and doxorubicin group. These results may be due to that ginseng has protective effect on hepatic cells and improved serum albumin (Song et al. 2004).

Regarding antioxidant state, Doxorubicin administrated rats showed significant elevation in MDA beside significant reduction in SOD, CAT, GSH and GSH-Px. Similar results were observed in previous studies (Mohamed et al. 2015, Faten et al. 2018, Haybar et al. 2019). Xipeng et al. (2017) showed that doxorubicin increased MDA coupled with reduction in SOD, CAT, GSH and GSH-Px in rats. These findings may be attributed to the generation of free radicals and the induction of oxidative stress induced by doxorubicin administration (El-Maddawya \& Abdel-Naby 2019, Injac et al. 2008).

Rats received ginseng alone showed significant increase in serum SOD, CAT, GSH and GSH-Px associated with non-significant decrease in MDA compared with control group. Similar results were reported by Fu \& Ji (2003) and Kyu et al. (2013). Wan et al. (2007) showed that ginseng extracts induce elevated in antioxidant enzymes. Furthermore, these results are consistent, partially, with the previous results by Kim et al. (2016) who showed a reduction in MDA beside increase in SOD, CAT, GSH and GSH-Px in rats administrated with ginseng. Based on human study, Kim \& Park (2003) reported that the activity of SOD and CAT increased after administration of ginseng extract for eight weeks. 
Doxorubicin plus ginseng group showed non- significant changes in MDA and GSH levels and activities of CAT and SOD enzymes in comparison with control group. Meanwhile, this group revealed a significant increase in SOD activity associated with a significant decrease in MDA level compared with doxorubicin group. These results in accordance, partially, with those reported by Young et al. (2019) who reported that ginseng enhance the activity of the antioxidant enzymes (SOD, CAT, GSH and GSH-Px) on doxorubicin-induced toxicity in rats. The improving effect of ginseng may be explained by what was reported by Kitts et al. (2000) that ginseng extract have the ability to scavenge superoxide radicals and inhibit lipid peroxidation through transition metal chelation.

Concerning male fertility evaluation, Rats that received doxorubicin displayed significant reduction in sperm count, motility present, a live sperm present and testosterone level beside significant elevation in sperm abnormality percent. These results are in consistent with those achieved by El-Maddawya \& Abd-ElNaby (2019). They reported a significant decrease in sperm count, motility \%, and live sperm \%, a significant increase in sperm abnormalities with a significant decrease of the testosterone level in doxorubicin treated rats. These results are supported by Yokochi \& Robertson (2004). They reported that doxorubicin induced male infertility. Notably, Hou et al. (2005) found that a single dose of doxorubicin administration to the immature rat resulted in acute cytotoxic effect on testis. In addition, Semet et al. (2017) showed that doxorubicin induced drop in testosterone level leading to reduction in sperm production and sperm characters. The obtained results are in harmony with Vendramini et al. (2010) who showed reduction of sperm concentration and motility and an increase of sperm anomalous forms in doxorubicin-treated rats. They attributed these results to testicular toxicity occurred by doxorubicin that induced apoptosis for mitotically dividing spermatocytes and intermediate spermatogonia.

Rats that received ginseng alone showed significant increase in sperm cell concentration, sperm motility $\%$, and a live sperm $\%$ and testosterone hormone coupled with significant decrease in sperm abnormalities $\%$. The obtained results are supported by that obtained by Wan et al. (2007) who recorded that ginseng induced elevation in sperm cell concentration, sperm motility, alive sperm and testosterone hormone in rats. In addition, ginseng increases the production of spermatozoa and testosterone levels (Eskandari et al.

2017). Keeping with this line, Zakai et al. (2011) reported that ginseng improved seminal picture and attributed these results to direct effects of ginseng on the central nervous and reproductive systems. Salvati et al. (1996) and Hosseini et al. (2012) added that ginsenosides has stimulatory effect on spermatogenesis in testis.

Rats that received ginseng plus doxorubicin showed significant increase in sperm count, sperm motility \%, live sperm present and testosterone level associated with a significant decrease in sperm abnormality $\%$ in comparison with doxorubicin treated rats. These findings are in harmony with that reported by Jong et al. (2002) who reported that Coadministration ginseng may be partially protective against doxorubicin-induced testicular toxicity and fertility in mice. To clarify these results, it is important to note that increases in the levels of antioxidant enzymes leading to improve male fertility and biochemical parameters (El-Saieed 2003). It is worth mention that ginseng is a powerful antioxidant and has an extensive range of functions including induction of spermatogenesis and activation of either glial cell line-derived neurotrophic factor (GDNF) or cyclic adenosine $3^{\prime}, 5^{\prime}$-monophosphate (cAMP)-responsive element modulator (CREM) in rat testes (Van Kampen et al. 2003, Kang et al. 2006).

\section{Conclusion}

It could be concluded that doxorubicin affects the male fertility and biochemical parameters. Using antioxidant (ginseng) induces ameliorations in adverse effect of doxorubicin. So, it is good to use antioxidant with doxorubicin.

\section{References}

[1] Abdalla AN, Almaliki WH, Mukhtar MH, Anwar F, Shahid I, Menshawi SA \& Alsulimani TS (2016). Ameliorative Influence of Dietary Dates on Doxorubicin-Induced Cardiac Toxicity. Pharmacology \& Pharmacy 7:34-39 .https://doi.org/10.4236/pp.2016.78042.

[2] Akash A, Ji Hye K, Jong HK, Young SY \& Jae YC (2018). Functional role of ginseng-derived compounds in cancer. Journal of Ginseng Research 42:248 -254. https://doi.org/10.1016/j.jgr.2017.04.009.

[3] Al-Sowayan. NS \& Nadia HM (2014). The Protective Effect of Grape Seed Extract on Cardiotoxicity Induced by Doxorubicin Drug in Male Rats. Advances in Bioscience and Biotechnology 5:1078-1089 .https://doi.org/10.4236/abb.2014.514123.

[4] Arcamone F, Cassinelli G, Fantini G \& ale (1969). Adriamycin, 14-hydroxydaunomycin, a new antitumor antibiotic from S. peucetius var. caesius. Biotechnol Bioeng 11:1101-1110. https://doi.org/10.1002/bit.260110607.

[5] Bauer J (1982). Colorimetric Determination of Serum albumin. Clinical LaboratoryMethods 4th Ed.:495-496.

[6] Bearden H \&Flaquary J (1980). Applied Animal Reproduction. Reston Publish-4th Ed Co, JncReston, Virginia:PP.158-160.

[7] Beutler E, Duran O \& Kelly B (1963). Improved method for the determination of blood glutathione. J Lab and Clin Med 61:882.

[8] Brilhante O, Stumpp T \& Miraglia SM (2011). Long-term testicular toxicity caused by doxorubicin treatment during pre-pubertal phase. International J of Medicine and Med Sci 3:52-60.

[9] Buhl S \& Jackson K (1978) . Determination of serum locatate dehydrogenase. Clin Chem 24:858.

[10] Chen X, Zhang Y, Zhu Z, HL, Guo H, Xiong C, Xie K, XZ \& Su S (2016). Protective effect of berberine on doxorubicin-induced acute hepatorenal toxicity in rats. Mol Med Rep J 13:53-60. https://doi.org/10.3892/mmr.2016.5017.

[11] Doumas B, Baysa D, Carier R \& R. S (1981). determination of total protein in serum. I development and validation. Clin Chem 27:1642-1650. https://doi.org/10.1093/clinchem/27.10.1642.

[12] El-Maddawya ZK \& AbdEINaby WSH (2019). Protective effects of zinc oxide nanoparticles against doxorubicin induced testicular toxicity and DNA damage in male rats. Toxicology Research 8:654-662 https://doi.org/10.1039/c9tx00052f.

[13] El-Saieed M (2003). Gensing reduce hepatic damage induced by 2, 3, 7, 8. tetrachor-dibenzopdioxin in rats. JEgyptVetMedAss 63:205-216.

[14] Eskandari M, Arash GL, Habib Z, Aram R, Mohammad TK, Hossein E \& S S (2017). Co-administration of ginseng and ciprofloxacin ameliorates epididymo-orchitis induced alterations in sperm quality and spermatogenic cells apoptosis following infection in rats. Andrologia 49:134-148. https://doi.org/10.1111/and.12621.

[15] Fadya KAA, Fayza EA, Mohamed AGS \& Samar AMY (2019). A Comparative Study of the Ameliorative Effect of Doxorubicin with Vitamin E versus Liposomal Doxorubicin on the Left Ventricular Histological and Immunohisochemical Changes Induced by Doxorubicin in Adult Male Albino Rats. Egypt J of Histo 42:67-81 .https://doi.org/10.21608/ejh.2019.7015.1061.

[16] Faten Madmd, MD Ras, MD Nn \& M Sc Cmw (2018). Effect of Short-Term Swim Exercise on Cardiac Dysfunction Induced by Doxorubicin in Rats. . Med J Cairo Univ 86:405-416 .www.medicaljournalofcairouniversity.net https://doi.org/10.21608/mjcu.2018.55140.

[17] Frederick C, Williams L \& Wang A (1990). Structural comparison of anticancer drug-DNA complexes: adriamycin. Biochemistry 29:538-549. https://doi.org/10.2210/pdb1d12/pdb.

[18] Fu Y \& Ji L (2003). chronic ginseng consumption attenuates age-associated oxidative stress in rats. The Journal of Nutrition133:3603-3609. https://doi.org/10.1093/jn/133.11.3603.

[19] Haybar H, Goudarzi M, Mehrzadi S, Aminzadeh A, Javad M, KhodayarMojtaba \& Fate K (2019). Effect of gemfibrozil on cardiotoxicity induced by doxorubicin in maleexperimental rats. . Biomedicine \& Pharmacotherapy 109:530-535 .https://doi.org/10.1016/j.biopha.2018.10.101. 
[20] Hellmann K (1999). Preventing the cardiotoxicity of anthracyclines by dexrazox-ane A real breakthrough. BMJ 23:1085-1086. https://doi.org/10.1136/bmj.319.7217.1085.

[21] Hess FG, Jr Rap, G E Coxt KRS \& Becci Pj .(1982) Reproduction study in rats on gensing extracts G115. Food and Chemical Toxicology. 20:189192 .https://doi.org/10.1016/S0278-6915(82)80246-9.

[22] Hong B, YH. J, JH. H, KY. N \& TY. A (2002). A double-blind crossover study evaluating the efficacy of Korean red ginseng in patients with erectile dysfunction: a preliminary report. Journal of Urology 168:2070-2073. https://doi.org/10.1016/S0022-5347(05)64298-X.

[23] Horder M \& Elsner R (1991). Approved Recommendation of IFCC Methods for the Measurement of Catalytic Concentration of Enzymes, Part 7 IFCC Method for Creatine Kinase. . J Clin Chem Clin Biochem 29:435-443.

[24] Hosseini A, Abbas A \& Samad Z (2012). Beneficial Effects of American Ginseng on Epididymal Sperm Analyses in Cyclophosphamide Treated Rats. Cell J. 14(2): 116-121. https://doi.org/10.1158/0008-5472.CAN-05-2004.

[25] Hou M, Chrysis D, Nurmio M, Parvinen M, Eksborg S, So“der O \& Jahnukainen K (2005). Doxorubicin induces apoptosis in germ line stem cells in the immature rat testis and amifostine cannot protect against this citotoxicity. Cancer Res 65:9999-10005 .Doi: 10.1158/0008-5472.CAN-052004

[26] Injac R, Perse M, Obermajer N, Djordjevic-Milic V, Prijatelj M, Djordjevic A, Cerar A \& Strukelj B (2008). Potential hepatoprotective effects of fullerenol $\mathrm{C} 60(\mathrm{OH}) 24$ in doxorubicin-induced hepatotoxicity in rats with mammary carcinomas. Biomaterials 29:3451-3460. https://doi.org/10.1016/j.biomaterials.2008.04.048.

[27] Issa N \& El-Sherif N (2017). Effect of Ginseng on the Testis of Subclinical Hypothyroidism Model in Adult Male Albino Rat. Austin J Anat 4:1065. https://doi.org/10.26420/austinjanat.2017.1065.

[28] Jang D, Lee M, Shin B, Lee Y and Ernst E (2008). Red ginseng for treating erectile dysfunction: a systematic review. Br JClin Pharmacol 66:444450 .https://doi.org/10.1111/j.1365-2125.2008.03236.x.

[29] Jang M, Woo J, M. J \& Chun G (2011). Effects of red ginseng extract on the epididymal sperm motility of mice exposed to ethanol international. Journal of Toxicology 30(4) 435-442 .https://doi.org/10.1177/1091581811405074.

[30] Jimenez A, Meckes M, Ramireez R, Torres J \& Luna J (2003). Activity against multidrug-resistant mycobacterium tuberculosis in Mexican plants used to treat respiratory diseases. J Phytother Res 17:903-908. https://doi.org/10.1002/ptr.1377.

[31] Jong K, Young J, Kyong O \&Eun Y (2002). Ginseng intestinal metabolite -I (GIM-I) reduces doxorubicin toxicity in mouse testis. . Reprod Toxic 16:91-98. https://doi.org/10.1016/S0890-6238(02)00021-7.

[32] Jun YQ, GenJin Y, LiLi W, YongLong H, Yan H, Jie L, JinLu H, Jin L, Run G \& Cheng G (2017). Protective Effects of Dexrazoxane against Doxorubicin-Induced Cardiotoxicity:A Metabolomic Study. PLoS One 12:1-18 .https://doi.org/10.1371/journal.pone.0169567.

[33] Kamel A \& Lotfy H (2006). Effect of gensing extract on some hormonal and immunological parameters in male New Zealand rabbits. VetMedJ 54:53-65.

[34] Kang K, Kim H, Pyo J \&Yokozawa T (2006). Increase in the free radical scavenging activity of ginseng by heat-processing. Biol Pharm Bull 29:750-754 https://doi.org/10.1248/bpb.29.750.

[35] Kato M, Makino S, Kimura H \& al. e (2001). Sperm motion analysis in rats treated with Adriamycin and its applicability to male reproductive toxicity studies. Journal of Toxicology Science. 26:51-59 https://doi.org/10.2131/jts.26.51.

[36] Kim S \&Park K (2003). Effects of Panax ginseng extract on lipid metabolism in humans. . Pharmacol Res 48:511-513. https://doi.org/10.1016/S1043-6618(03)00189-0.

[37] Kim MH, Lee EJ, Cheon JM, Nam KJ, Oh TH \& Kim K-S (2016). Antioxidant and hepatoprotective effects of fermented red ginseng against high fat diet-induced hyperlipidemia in rats. Laboratory Animal Research 32:217-223. https://doi.org/10.5625/lar.2016.32.4.217.

[38] Kitts DD, ANW \& Hu C (2000). Antioxidant properties of a North American ginseng extract. Molecular and Cellular Biochemistry volume 203:110. https://doi.org/10.1023/A:1007078414639.

[39] Kyu H, Dukhwan K \&Jong H (2013). Cardio protective potential of red ginseng on isoproterenol-induced cardiac injury in rats. Journal of ginseng research 37:73-82 https://doi.org/10.5142/jgr.2013.37.273.

[40] Lee SH, Choi KH, Cha KM, Hwang SY, Park. UK, Jeong MS, Hong JY, Han CK, In G, Kopalli SR \& Kim SK (2019). Protective effects of Korean Red Ginseng against sub-acute immobilization stress-induced testicular damage in experimental rats. Journal of ginseng research 43:125134 https://doi.org/10.1016/j.jgr.2017.09.002.

[41] Marinelo J, Delratlo M \& Caprico G (2018). Anthracyclines as Topoisomerase II Poisons: From Early Studies to New Perspectives. International Journal of Molecular Sciences 19:48-49 https://doi.org/10.3390/ijms19113480.

[42] Mohamed H, Mohamed M, Ayman F \& Ahmed F (2015). Biochemical effects of spirulina platensis against oxidative stress caused by doxorubicin. Benha Veterinary Medical Journal 28:147-154. https://doi.org/10.21608/bvmj.2015.32493.

[43] Nair R, Sellaturay S \& Sriprasad S (2012). The history of ginseng in the management of erectile dysfunction in ancient China (3500-2600 BCE). Indian J Urol 28:15-20. https://doi.org/10.4103/0970-1591.94946.

[44] Nielsen F, Mikkelsen B \&Grandjean P (1997). Plasma malondialdehyde as biomarker for oxidative stress. Reference interval and effects of life style factors.Clin Chem 43:1209-1214. https://doi.org/10.1093/clinchem/43.7.1209.

[45] Nishikimi M, Appaji R \& Yagi K (1972). Occurance of superoxide anion in the reaction of reduced phenazine methosulfate and molecular oxygen Bio Chem. Biophys Res Com 46:849-854. https://doi.org/10.1016/S0006-291X(72)80218-3.

[46] Okada S \& Zhang D (1998). Gensing extract protects unsaturated fatty acids from decomposition caused by iron-mediated lipid peroxidase advances in gensing Res. Proceeding of the 7th Interational Symposium on Gensing Seoul,Korea,22-25

[47] Osama M, Manal M, M. A \& El-Zahraa S (2019). Camellia sinensis, epicatechin abate doxorubicin-induced hepatotoxicity in rats via their modulatory effects on oxidative stress and apoptosis. Journal of Applied Pharmaceutical Science 9:30-44. https://doi.org/10.7324/JAPS.2019.90405.

[48] Paglia DE \& Valentine WN (1967). Studies on the quantitative and qualitative characterization of erythrocyte glutathione peroxidase. J Lab Clin Med 70:158-169.

[49] Park S, Lim K, Noh J, Jeong E, Kim J, Han B \& Moon SK (2013). Moon subacute oral toxicity study of korean red ginseng extract in spraguedawley rats. Toxicological Research .29(4):285-292. https://doi.org/10.5487/TR.2013.29.4.285.

[50] Patil L \& Balaraman R (2009). Effect of Melatonin on Doxorubicin induced testicular damage in rats. International Journal of PharmTech Research1:879-884.

[51] Pugazhendhi A, Edison I, Jacob J \& Karuppusamy I (2018). Toxicity of Doxorubicin (Dox) to different experimental organ systems. Life Sciences 200:26-30 .https://doi.org/10.1016/j.lfs.2018.03.023.

[52] Reitman S \& Frankel S (1957). Acolorimetric determination of serum gluta-mic oxalacetic and glutamic pyruvic transaminase. Am. J Clin Path 28:56-60. https://doi.org/10.1093/ajcp/28.1.56.

[53] Saber AS, Nahed SB, Mona AS, Mahmoud M \& Hassan MA (2013). Biochemical alterations in hepatocellular carcinoma patients treated with doxorubicin. Res Bio Sci 7:468-475.

[54] Salvati G, Genovesi G \& Paolini P (1996). Effects of Panax Gensing C.A. Meyer saponins on male fertility. Panminerva Med 38:249-254.

[55] Semet M, Paci M, Sa€ıas Magnan J, Metzler Guillemain C, Boissier R, Lejeune H \& Perrin J (2017). the impact of drugs on male fertility: a review. Andrology 5:640-663 https://doi.org/10.1111/andr.12366.

[56] Shihong C, Zhijun W, Ying H, Stephen AOB, Rebecca AW, Steven Y \& Moses SSC (2014). Ginseng and Anticancer Drug Combination to Improve Cancer Chemotherapy: A Critical Review.Evidence-Based Complementary and Alternative Medicine45:168-179. https://doi.org/10.1155/2014/168940.

[57] Shivakumar P, Rani MU, Reddy AG \& al e (2012). A Study on the Toxic Effects of Doxorubicin on the Histology of Certain Organs. Toxicol Int 19:241-244. https://doi.org/10.4103/0971-6580.103656. 
[58] Singh G, Singh A \& Abraham A (2008). Protective effect of Terminalia arjuna against doxorubicin induced cardiotoxicity. J Ethno pharma 117:123-129 .https://doi.org/10.1016/j.jep.2008.01.022.

[59] Sinha K (1972). Colorimetric assay of catalase. Anal Biochem 47:89-94. https://doi.org/10.1016/0003-2697(72)90132-7.

[60] Song. J-Y, Akhalaia. M, Platonov. A, Kim. H-D, Jung. I-S, Han. Y-S \& Yun. Y-S (2004) .Effects of Polysaccharide Ginsan from Panax ginseng on Liver Function. Arch Pharm Res 27:531-538. https://doi.org/10.1007/BF02980127.

[61] Sridevi. T (2011). Effect of doxorubicin on the biochemical activities of the male reproductive system of white mice, Mus musculus. Indian Journal of Science and Technology 4:15-20.

[62] Tambane \& Dunlop (2000). Statistics and Data Analysis from Elementary to Intermediate. Prentic Hall Ajitc. Tampbne Dorothy Dunlop, 2000.

[63] Van Kampen J, Robertson H, Hagg T \& Drobitch R (2003). Neuroprotective actions of the ginseng extract G115 in two rodent models of Parkinson's disease. Exp Neurol.184(1):521-529. https://doi.org/10.1016/j.expneurol.2003.08.002.

[64] Vendramini V, Sasso-Cerri E \& Miraglia S (2010). Amifostine reduces the seminiferous epithelium damage in doxorubicin-treated prepubertal rats without improving the fertility status. Reproductive biology and endocrinology : RB\&E 8:3 .https://doi.org/10.1186/1477-7827-8-3.

[65] Vesna Jcc, Viktorija Dc-Sc, Željka Tc, Silva Dc, Dubravko Bc, Aleksandra Kcc, Eugenie N, Martin V \&Kamil Kc (2018). the efficacy of amifostine against multiple- dose doxorubicin- induced toxicity in rats. Int J Mol Sci 19:2370 .https://doi.org/10.3390/ijms19082370.

[66] Wan S, Dong Y, Dorim K \& Wong M (2007). Korean ginseng induces spermatogenesis in rats through the activation of cAMP-responsive element modulator. Fertility and sterility 88:1000-1002 .https://doi.org/10.1016/j.fertnstert.2006.12.014.

[67] Wilson J \&Foster D (1992). Williams text book of Endocrinology . 1st Ed, chapter 6 pp 923-926 Saunders co, Philadelphia Santener, S.

[68] Xipeng SL L, Quan Y, Yan H, Yong LH \& Cheng G (2017). Scutellarin protects against doxorubicin-induced acute cardiotoxicity and regulates its accumulation in the heart. Arch Pharm Res 40:875-883 https://doi.org/10.1007/s12272-017-0907-0.

[69] Yagmurca. M, Bas. O, Mollaoglu. H ,Sahin. O, Nacar. A, Karaman. O \&Songur. A (2007). Protective Effects of Erdosteine on Doxorubicininduced Hepatotoxicity in Rats. Archives of Medical Research 38:380-385 .https://doi.org/10.1016/j.arcmed.2007.01.007.

[70] Yang C, Chen Y \& Chen C (2017). Assessment of doxorubicin-induced mouse testicular damage by the novel second-harmonic generation microscopy .Am J Transl Res 9:275-288.

[71] Yokochi T \& Robertson K (2004). Doxorubicin inhibits DNMT1, resulting in conditional apoptosis. Mol Pharmacol 66:1415-1420. https://doi.org/10.1124/mol.104.002634.

[72] Young JJ, Dongbin L, Mohammad A, Hossain., Aravinthan. A, Kang. C-W, Kim. NS \& Kim. J-H (2019). Korean Red Ginseng enhances cardiac hemodynamics on doxorubicin-induced toxicity in rats. Journal of ginseng Research. Available online 14 March 2019. Doi.org/10.1016/j.jgr.2019.03.002.

[73] Zakai F, Uddin S, Akram M, Mohiuddin E, Hannan A \& Usmanghani K (2011). Introduction to male infertility. J of Med Plants Res 5:5936-5945. 